\title{
Experimental evidence to support a patent application: are in silico data enough?
}

\author{
"...a balance must be struck between obtaining an early filing date and \\ meeting the requirements in relation to the amount and type of data needed to obtain \\ valid patent protection."
}

Keywords: in silico data $\approx$ patent $\approx$ pharmaceutical $\approx$ usefulness $\approx$ utility

The in silico discovery that a molecule may have an affinity for a target can form the start of an extensive program into the identification of new pharmaceuticals for the treatment of a disease or condition. Such a research program will typically involve testing the molecule in vitro and in vivo to confirm that the molecule has the desired agonist or antagonist activity, along with possibly modifying the molecule and further testing analogues to improve target affinity. However, this type of research and development can be very time consuming.

In highly populated areas of research there could be a rush to secure patent protection before competitors. However, filing too early, and without sufficient experimental evidence to support your patent application could jeopardize your chances of obtaining patent protection. Therefore, a balance must be struck between obtaining an early filing date and meeting the requirements in relation to the amount and type of data needed to obtain valid patent protection.

\section{Utility}

Patents may only be granted for subject matter that has some practical application. What is required for a patent to demonstrate utility can be better understood by considering how this requirement is applied in different jurisdictions.

\section{- United States of America}

The US Patent Code includes the requirement that "whoever invents or discovers any new and useful process, machine, manufacture, or composition of matter, or any new and useful improvement thereof, may obtain a patent therefore" [1]. It is also necessary that the patent specification contains a written description of the invention and of the manner and process of making and using it, so that a person skilled in the art can make and use the invention [2]. These two requirements make up the 'utility requirement' in the USA. For this two-part requirement to be satisfied, the patentee must provide specific, substantial and credible evidence of utility [3].

For an invention relating to the medical use of a pharmaceutical active to be considered to have specific and substantial utility, it is necessary to demonstrate that the invention has a particular use [4]. Stating that a pharmaceutical active has the potential for use in the treatment of any disease will not be sufficient to meet the utility requirement.

In addition, a patent specification that contains no data at all to prove that the pharmaceutical active is able to achieve the claimed medical use, will not be considered to have specific or substantial utility [5]. However, the application does not need to contain excessive amounts of data; just enough to show that the pharmaceutical active possesses the claimed activity and can be used to treat the disease or condition will be sufficient to demonstrate utility. For example, if the patent specification includes results of tests demonstrating the bioactivity of a new pharmaceutical active, such as the improved activity of a new substituted prostaglandin compared with the activity of naturally occurring prostaglandins, the utility requirement will be satisfied [6].

Credible utility will only be established if a person skilled in the art would appreciate that the pharmaceutical active actually exhibits the claimed biological activity. Evidence showing that a compound is a structural analogue of a known anticancer agent will only be considered credible if that evidence demonstrates activity of the claimed compounds in tests conducted in an appropriate model, such as an animal typically used in screening for anticancer agents [7].

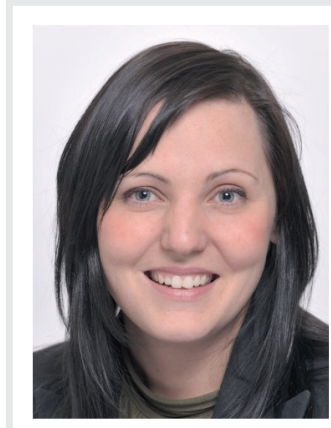

Jacqueline Satchell

Griffith Hack, Level 3, 509 St Kilda Road, Melbourne, 3004, Australia

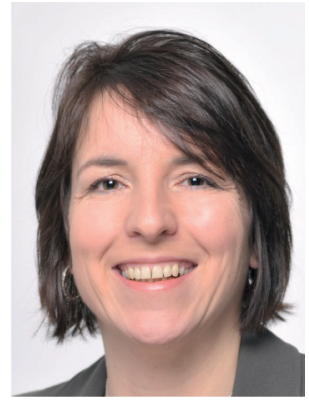

Amanda Stark

Author for correspondence: Griffith Hack, Level 3, 509 St Kilda Road, Melbourne, 3004, Australia Tel.: +61 392438300 E-mail: amanda.stark@griffithhack. com.au 
However, in vivo data are not essential, and credible utility may be established by provision of in vitro testing results. For example, in vitro results that show the pharmacological activity of the active compounds will be sufficient, while the onerous amounts of data necessary for regulatory approval are not required to demonstrate utility [8].

\section{- Europe}

Under European patent law, an invention will be considered as susceptible of industrial application if it can be made or used in any kind of industry, including agriculture [9].

The test for industrial application in Europe used to be similar to the specific, substantial and credible test used in the USA. However, the test in the European Patent Office and the UK Intellectual Property Office has recently moved away from this, and instead involves determining whether the proposed industrial application is plausible and has a sound and concrete technical basis [10].

To show that a claimed invention is industrially applicable, it is necessary that the specification identifies how the invention may be applied. For example, describing in the specification that a newly identified phosphatase can be made and used as a tool for further research with only hypotheses as to the actual role of the phosphatase in cell signaling and cancer, will not satisfy the industrial applicability requirement. This is because the application is vague and speculative and requires the reader to guess or carry out further work to identify a practical application for the claimed invention [11].

The specification must also indicate that the industrial application of the invention was known to the inventors, and not merely covered by the inclusion of a vast number of possible applications. An invention directed to a protein discovered by 'data mining' based on homology to known proteins was considered as failing the industrial applicability requirement as the specification only provided evidence of amino acid sequence homology, and made suggestions as to the possible therapeutic and diagnostic applications [12].

It is also necessary that the specification contains some data to verify the biological activity or effect that is described in the specification. For example, claims directed to a method for modulating ligand or anti-ligand binding of a receptor will not be industrially applicable if the claims are only supported by a homology-based prediction that a receptor has a particular activity, and no data are provided to verify the function of the receptor or to show which ligands are capable of modulating the receptor activity [13].

\section{Australia}

Under current Australian patent law, an invention, so far as claimed in any claim, must be useful [14]. This requirement is significantly lower than that in the USA or Europe.

In meeting the requirement of utility in Australia, it is necessary to ensure that the claimed invention meets the promise of the specification. Although a product may be useful for the treatment of a particular indication, failure to meet an assertion in the specification that a product has surprising activity could result in a lack of utility of the claimed pharmaceutical product $[15,16]$. For example, a patent that described and claimed compounds as being useful as antivirals, when, in fact, the compounds were too toxic for use as antivirals and, instead, were useful as anticancer agents, was considered to present a "fairly persuasive prima facie case" of lack of utility [17]. However, very few patents have been found invalid for utility, and the courts have even given the patentee the benefit of the doubt where an 'obvious modification' would result in the claims meeting the utility requirement [18].

The position in Australia is set to change to be more in line with the US requirements by amendment of the Patents Act 1990 to state that the specification must disclose a specific, substantial and credible use for the claimed invention [101].

\section{What kind of data is actually required}

Based on existing case law, the requirement that the invention must show utility will not be met by an application that includes only data that a skilled person would not consider to be a credible showing of that utility. In silico binding data is only a prediction as to whether a particular chemical structure will bind to an enzyme or receptor, and thus serves as a prediction as to what will occur in reality. In the absence of 'real' data, the person skilled in the art must perform further experiments in order to determine what subject matter will achieve the aims stated in the specification. For example, an application containing only in silico data, but containing claims directed to the use of compounds identified by in silico screening 
to treat a particular disease, does not demonstrate that these compounds can actually act as agonists or antagonists of the target enzyme or receptor, or that the compounds can treat the disease. Valid patent protection may only be obtained if the applicant has shown that the compounds actually work, that is, that they are biologically active in vitro and/or in vivo. The lack of data to support the biological activity could also lead to invalidity of a patent on the basis that the invention is not described in sufficient detail for a person skilled in the art to make or use the invention, or because the best method of performing the invention is not disclosed $[19,20]$.

\section{How much data are required?}

To ensure that a patent is entitled to its earliest priority date, it will be necessary to ensure that the provisional application demonstrates that the invention is useful and thus satisfies the utility requirement. Therefore, on filing a provisional application, the application should include at least one in vitro example showing that the pharmaceutical active has the desired biological activity. In this situation it is important to ensure that the one in vitro test is an appropriate test that a person skilled in the art would understand to be indicative of the pharmaceutical active being capable of treating the particular disease or condition that is the subject of the claims.

Twelve months from the date of filing the provisional application, on filing a PCT application or direct filings in the jurisdictions of interest ('complete applications'), further examples that support the initial in vitro result can be added. The type and amount of further data that are required to support a complete application including claims directed to the use of a pharmaceutical active for a medical use varies between jurisdictions but, in most cases, if a complete application includes a claim to a therapeutic use of the compounds, it will be necessary to also provide at least in vitro data. It is of course the case that more data

\section{Bibliography}

1 United States Patent Code 35 USC 101 (2010).

2 United States Patent Code 35 USC 112, first paragraph (2010).

3 Manual of Patent Examining Procedure Edition 8. US Government Printing Office, Washington, DC, USA (2010).

supporting the initial in vitro experiments that can be included in the complete application, the better.

\section{Post-filed data}

Certain requirements for patentability, such as inventive step, may be satisfied by filing experimental evidence during patent prosecution. However, it is not possible to submit data after filing to remedy deficiencies in the specification in respect of utility. The application must contain appropriate data at the priority date to show that the invention has utility.

\section{Conclusion}

In competitive fields it may be desirable to file patent applications as soon as you have identified that a particular molecule may have biological activity against a particular disease or condition. However, filing too early may prevent you from obtaining valid patent protection. It is important to ensure that a provisional application contains at least some experimental data to establish that the invention is in fact useful for the stated purpose. If data are only included at the complete stage, the patent may not be entitled to its earliest priority date, and a later application filed by a competitor could become invalidating prior art against your invention.

In silico data indicating that a particular molecule may have biological activity will not be enough to support a provisional application. However, one laboratory experiment confirming this discovery can be enough to ensure an invention satisfies the requirement that the invention is useful.

\section{Financial \& competing interests disclosure}

The authors have no relevant affiliations or financial involvement with any organization or entity with a financial interest in or financial conflict with the subject matter or materials discussed in the manuscript. This includes employment, consultancies, honoraria, stock ownership or options, expert testimony, grants or patents received or pending, or royalties. No writing assistance was utilized in the production of this manuscript.

4 re Fisher. 421 F.3d at 1374, 76 USPQ2d at 1232 .

5 re 318 Patent Infringement Litigation. Fed. Cir. 2009-1594, 25 September 2009.

6 Nelson vs Bowler, 626 F.2d 853, 856, 206 USPQ 881, 883 (CCPA 1980).

7 re Jolles, 628 F.2d 1322, 206 USPQ 885 (CCPA 1980).
8 Cross vs Iizuka, 753 F.2d 1040, 1051, 224 USPQ 739, 747-48 (Fed. Cir. 1985).

9 European Patent Convention, Article 57 (2000).

10 Examination Guidelines for Patent Applications relating to Biotechnological Inventions in the Intellectual Property Office. UK Intellectual Property Office, Newport, UK (2009). 


\section{EDITORIAL | Satchell \& Stark}

11 Max-Planck/BDP1 Phosphatase T 0870/04, European Patent Office (2005).

12 Eli Lilly vs Human Genome Sciences Inc EWHC 1903 (Pat) (Patents Court) (2008).

13 ICOS Corporation, OJ European Patent Office, 293 (2002).

14 Australian Patents Act 1990 (Cth) Section 18(1)(c) (1990).

15 Ranbaxy Australia Pty Ltd vs Warner-Lambert Company LLC, (No 2) FCA (2005).
16 Ranbaxy Australia Pty Ltd vs Warner-Lambert Company LLC, FCAFC 82 (2008).

17 Interpharma Pty Ltd vs Commissioner of Patents FCA 1498 (2008).

18 Rescare Ltd vs Anaesthetic Supplies Pty Ltd 111 ALR 205 (1992).

19 European Patent Convention Article 83, 35 USC 112, first paragraph (2010).

20 Australian Patents Act 1990 s40(2)(a) (1990).

\section{- Website}

101 The Parliament of the Commonwealth of Australia, Senate, Intellectual Property Laws Amendment (Raising the Bar) Bill 2011. www.ipaustralia.gov.au/pdfs/news/ip_laws_ exposure_draft_explanatory_memo.pdf 